\title{
Biocompatibility of Wheat and Tomato in a Dual Culture Hydroponic System
}

\author{
Andrew C. Schuerger ${ }^{1}$ \\ Department of Plant Pathology, Walt Disney World Company, The Land, \\ Epcot, P.O. Box 10000, Lake Buena Vista, FL 32830
}

Philip D. Laible

Section of Plant Biology, Cornell University, 230 Plant Science, Ithaca, NY 14853

Additional index words. allelopathy, controlled ecological life support system, CELSS, space agriculture

\begin{abstract}
Yecora Rojo' wheat (Triticum aestivum L.) and 'Florida Petite' tomato (Lycopersicon esculentum Mill.) plants were grown in monocultured or intercropped recirculating hydroponic systems to determine whether plant growth or yield would be affected by intercropping. Mean fruit weight was slightly lower (12\%) for intercropped than for monocultured tomato plants. The number of tillers per plant was slightly lower $(7 \%)$ for wheat, and grain dry weight per plant and mean seed dry weight were slightly higher $(14 \%$ and $15 \%$, respectively) for intercropped than for monocultured plants. A lettuce seedling bioassay showed no evidence of allelopathic compound accumulation in monocultured or intercropped hydroponic systems.
\end{abstract}

Hydroponic systems likely will be used to grow higher plants in controlled ecological life support systems (CELSS), and several types of plant-growing systems have been proposed or developed for this purpose (Brown et al., 1992; Dreschel and Sager, 1989; Olson et al., 1988; Prince and Knott, 1989). A multispecies CELSS likely will afford greater stability of life support functions than a CELSS relying on few plant species (Cooke, 1971; Cooke et al., 1968; Odum, 1963). In a multispecies CELSS module, diverse plant species may be grown in close proximity to each other, possibly sharing common nutrient or gas loops. As multispecies plant production systems are developed, one critical question is the biocompatibility of the plant species. Plant allelopathic compounds have been reported for diverse plant species selected for study in CELSS (Akram and Hussain, 1987; Oleszek, 1987; Peterson and Harrison, 1992; Rice, 1984). Our objectives were to determine if plant growth or yield differed among monocultured and intercropped wheat and to-

Received for publication 17 Dec. 1993. Accepted for publication 10 May 1994. We thank Christopher S. Brown, Frederick L. Petitt, and Raymond M. Wheeler for their editorial comments and Bryan Kliewer and William Hammer for technical assistance. Research was conducted at The Land, Epcot, Lake Buena Vista, Fla. This project was jointly supported by the Walt Disney World Co. and the National Aeronautical and Space Administration (NASA), Biological Operations and Research Office, Kennedy Space Center, Fla. Mention of a brand name does not imply endorsement of the product by the Walt Disney World Co. or NASA, nor imply its approval to the exclusion of other products that may be suitable. The cost of publishing this paper was defrayed in part by the payment of page charges. Under postal regulations, this paper therefore must be hereby marked advertisement solely to indicate this fact.

${ }^{1}$ To whom reprint requests should be addressed. mato plants and to test whether allelopathic compounds accumulated in the nutrient solutions in which the plants were grown.

\section{Materials and Method}

Plant culture systems. A hydroponic plant culture system was constructed with three independent recirculating nutrient film technique (NFT) units (Fig. 1) and placed in an airconditioned greenhouse. High-pressure sodium lamps provided $\approx 80 \%$ of the 900 to 1200 $\mu \mathrm{mol} \cdot \mathrm{m}^{-2} \cdot \mathrm{s}^{-1}$ of the photosynthetically active radiation (PAR) that plants received $16 \mathrm{~h} /$ day; $20 \%$ of PAR was provided by ambient daylight. Temperature and relative humidity ranged between 23 to $28 \mathrm{C}$ and $55 \%$ to $80 \%$, respectively, for the duration of the experiment. Twelve plant-growth trays were divided equally among the three NFT units such that two trays per NFT unit were on each of two vertically separated levels (Fig. 1).

Hydroponic solutions were composed of the following inorganic salts (in $\mathrm{mM}$ ): 4.51 $\mathrm{Ca}\left(\mathrm{NO}_{3}\right)_{2} \cdot 4 \mathrm{H}_{2} \mathrm{O}, 3.48 \mathrm{KNO}_{3}, 1.15 \mathrm{KH}_{2} \mathrm{PO}_{4}$, and $1.75 \mathrm{MgSO}_{4} \cdot 7 \mathrm{H}_{2} \mathrm{O}$; and (in $\mu \mathrm{M}$ ): 0.04 $\mathrm{H}_{3} \mathrm{BO}_{4}, 6.75 \mathrm{MnSO}_{4} \cdot \mathrm{H}_{2} \mathrm{O}, 4.59 \mathrm{ZnSO}_{4} \cdot 7 \mathrm{H}_{2} \mathrm{O}$, $3.5 \mathrm{CuCl}_{2} \cdot 2 \mathrm{H}_{2} \mathrm{O}, 0.007\left(\mathrm{NH}_{4}\right)_{6} \mathrm{Mo}_{7} \mathrm{O}_{24} \cdot 4 \mathrm{H}_{2} \mathrm{O}$, and $\mathrm{Fe}$ provided by equimolar concentrations (89.5) of $\mathrm{FeCl}_{3} \cdot 6 \mathrm{H}_{2} \mathrm{O}$ and diethylenetriaminepentaacetic acid. Sigma Chemical Co., St. Louis, provided all chemicals. Nutrient solution in each NFT system was independently maintained at $\mathrm{pH} 6$ by automatic controllers (model 7142; Cole-Parmer Instruments Co., Chicago) with the addition of a $0.5 \%$ (v/v) aqueous solution of $\mathrm{HNO}_{3}$. The initial conductivity of fresh nutrient solution was between 1500 and $1700 \mathrm{~S} \cdot \mathrm{cm}^{-1}$. As evapotranspiration depleted the nutrient solution in each NFT system, fresh nutrient solution was added weekly to maintain a 100-liter volume in each system.
'Yecora Rojo' spring wheat and 'Florida Petite' dwarf cherry tomato seeds were surface-sterilized in an aqueous solution of $2.5 \%$ $\mathrm{NaOCl}(\mathrm{v} / \mathrm{v})$ and $0.01 \%$ Tween 20 (v/v) (J.T. Baker Chemical Co., Phillipsburg, N.J.) for 15 min and rinsed three times with sterile deionized water. Then seeds were planted in $27-\mathrm{cm}^{3}$ Grodan-rockwool cubes (Agro Dynamics, East Brunswick, N.J.) at two seeds per cube before being transplanted into the NFT systems. Tomatoes were thinned to one plant per cube 10 to 11 days after seeding. At transplant, tomato and wheat seedlings were 21 and 10 days old, respectively. After transplant, hydroponic trays were flooded with $2.5 \mathrm{~cm}$ of standing nutrient solution for 3 to 5 days to help initiate root development into the plant-growth trays; after 5 days, nutrient solution was recirculated through each tray at 1 liter $\cdot \mathrm{min}^{-1}$.

Treatments consisted of two NFT systems, each containing either wheat or tomato plants as monocultures, and a third NFT system intercropped with both crops. In the monocultured NFT systems, either 12 rockwool cubes of wheat ( 24 seeds planted at two seeds per cube) or eight rockwool cubes of tomato (one plant per cube) were planted in each of four trays. In the intercropped NFT system, six rockwool cubes of wheat (12 seeds planted at two seeds per cube) were placed in the rear half, and four rockwool cubes of tomato (one plant per cube) were placed in the front half of each of four trays. Pollination of tomatoes was achieved by vibrating the blossom clusters on each plant daily with an electric toothbrush. The experiment was conducted four times, with each repetition lasting 61 days after transplant.

At harvest, plant dry weights were determined for tomato and wheat. In addition, the numbers of fruit, total fruit fresh weight, and mean fruit fresh weight were determined per tomato plant. For wheat, number of tillers per plant, grain dry weight per plant, average dry weight for individual seed, average seed count per grain-bearing tiller, and total seed count per plant were determined

Allelopathic bioassays of nutrient solutions. A plant bioassay (Schuerger and Mitchell, 1992) was used to determine whether plant allelopathic compounds accumulated in nutrient solutions from the NFT systems. 'Great Lakes' lettuce (Lactuca sativa L.) seeds were surface-sterilized and germinated on nutrient solution agar (Schuerger and Mitchell, 1992) that contained nutrient solution samples obtained weekly from the NFT systems. Lettuce seedlings were incubated for 3 days at $25 \mathrm{C}$ in an incubator (model I-30BLL; Percival Manufacturing Co., Boone, Iowa), and then root lengths were measured with a color video camera electronically coupled to a Microcomp integrated video image analysis system (Southern Micro Instruments, Atlanta).

Statistical procedures. Plant growth and bioassay data were analyzed with a PC-based statistical analysis system (SAS Institute, Cary, N.C.). A completely randomized design was used, and the data were analyzed by $\mathrm{F}$ tests using the general linear models procedure $(P \leq$ $0.05)$. 


\section{Results and Discussion}

Intercropped tomato plants had slightly, but significantly, lighter (12\%) fruit than monocultured plants (6.8 vs. $7.7 \mathrm{~g}$, respectively). All other growth characteristics were similar for intercropped vs. monocultured tomato plants (plant dry weight, $23 \mathrm{vs.} 22 \mathrm{~g}$; fruit per plant, 42 vs. 39; fruit fresh weight per plant, 284 vs. 298 g). For wheat, plant dry weight, number of seeds per tiller, and total number of seeds per plant were similar among intercropped and monocultured tomato plants (Table 1). In contrast, the number of tillers per intercropped plant was slightly lower $(7 \%)$ and grain dry weight per intercropped plant was slightly higher (14\%) than for monocultured plants (Table 1). The increased grain yield for intercropped wheat plants likely was due to an increase $(15 \%)$ in individual seed weight per intercropped plant because the numbers of seeds per plant for the two treatments were similar (Table 1).

We found no evidence in the lettuce bioassays to support allelopathic compound accumulation in nutrient solutions. Root lengths of lettuce seedlings in bioassays were similar among samples from fresh nutrient solution and the monocultured and intercropped wheat and tomato plants (data not shown). Our bioassay results were similar to the results on plant growth in hydroponic systems used in

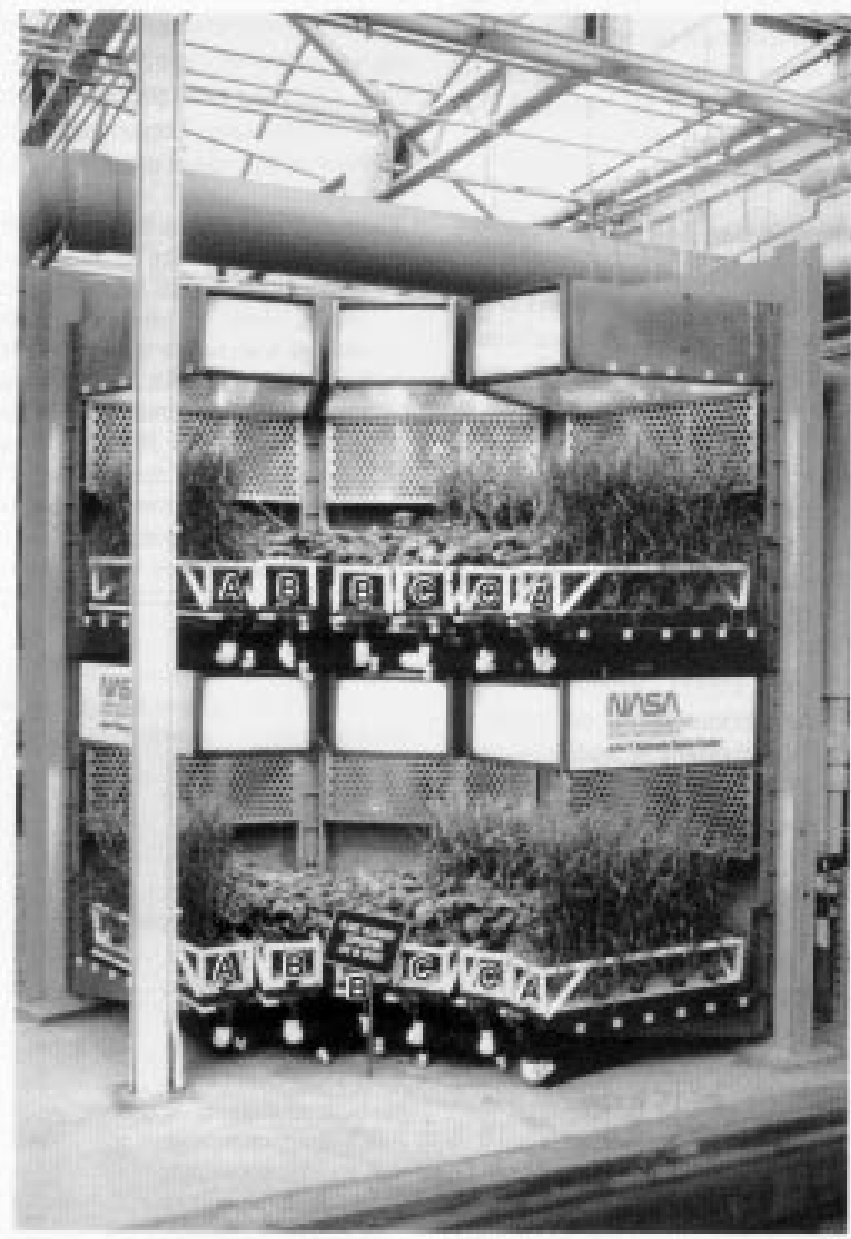

Fig. 1. Hydroponic plant-growth system with three independent nutrient film technique (NFT) units. Each NFT unit recirculated nutrient solution to four plant-growth trays. In this photograph, (A) monocultured wheat plants were planted on the outside of the hydroponic system, while trays for (B) monocultured tomato plants and $(\mathbf{C})$ intercropped tomato and wheat plants were planted together on the inside of the hydroponic system.

Table 1. Effects of intercropping with tomato on plant growth and yield of wheat in recirculating hydroponic systems.

\begin{tabular}{lcccccc}
\hline \hline & $\begin{array}{c}\text { Plant } \\
\text { dry wt } \\
(\mathrm{g})^{\mathrm{z}}\end{array}$ & $\begin{array}{c}\text { No. } \\
\text { tillers }^{\mathrm{z}}\end{array}$ & $\begin{array}{c}\text { Grain } \\
\text { dry wt } \\
(\mathrm{g})^{\mathrm{z}}\end{array}$ & $\begin{array}{c}\text { Individual } \\
\text { seed dry wt } \\
(\mathrm{mg})\end{array}$ & $\begin{array}{c}\text { No. seed/ } \\
\text { tiller }\end{array}$ & $\begin{array}{c}\text { Total no. } \\
\text { seed }^{\mathrm{z}}\end{array}$ \\
\hline Intercropped & 15.7 & $10.3^{*}$ & $7.2^{*}$ & $31.9^{*}$ & 21.9 & 225 \\
Monocultured & 14.7 & 11.1 & 6.3 & 27.8 & 20.9 & 228 \\
\hline
\end{tabular}

${ }^{2}$ Expressed as yield per individual plant.

*Significant at $P \leq 0.05$ for treatments in columns based on $\mathrm{F}$ test $(\mathrm{n}=16)$.

other studies in which no allelopathic compounds were detected (Hurd, 1978; Schuerger and Mitchell, 1992).

Our results indicate no significant adverse effects of intercropping tomato and wheat in a recirculating hydroponic system. The reasons for the slight increase in wheat yield in the intercropped NFT system or the slight decrease in mean fruit fresh weights in intercropped tomato plants are not known, but one possibility might be that root-to-root competition among wheat and tomato plants in the intercropped NFT system altered growth characteristics in wheat or tomato. Biocompatibility of different plants permits multispecies cropping schemes. In these schemes, a subset of each plant species is grown in several redundant CELSS modules in such a way that loss of any one module due to mechanical failure or disease outbreak would not cause the complete loss of any specific crop.

\section{Literature Cited}

Akram, M. and F. Hussain. 1987. The possible role of allelopathy exhibited by root extracts and exudates of chinese cabbage in hydroponics. Pakistan J. Sci. Ind. Res. 30:918-921.

Brown, C.S., W.M. Cox, T.W. Dreschel, and P.V. Chetirkin. 1992. The vacuum-operated nutrient delivery system: Hydroponics for microgravity. HortScience 27:1183-1185.

Cooke, G.D. 1971. Ecology of space travel, p. 498509. In: E.P. Odum (ed.). Fundamentals of ecology. Sanders College Publishing Co., Philadelphia.

Cooke, G.D., R.J. Beyers, and E.P. Odum. 1968. The case for the multispecies ecological system, with special reference to succession and stability, p. 129-139. In: J.F. Saunders (ed.). Bioregenerative systems. NASA Spec. Publ. 165, Washington, D.C.

Dreschel, T.W. and J.C. Sager. 1989. Control of water and nutrients using a porous tube: A method for growing plants in space. HortScience 24:944-947.

Hurd, R.G. 1978. The root and its environment in the nutrient film technique of water culture. Acta Hort. 82:87-97.

Odum, H.T. 1963. Limits of remote ecosystems containing man. Amer. Biol. Teacher 5:429443.

Oleszek, W. 1987. Allelopathic effects of volatiles from some Cruciferae species on lettuce, barnyard grass and wheat growth. Plant Soil 102:271273.

Olson, R.L., M.W. Oleson, and T.J. Slavin. 1988. CELSS for advanced manned mission. HortScience 23:275-286.

Peterson, J.K. and H.F. Harrison, Jr. 1992. Chemical factors involved in sweetpotato pest resistance and allelopathy, p. 263-272. In: W.A. Hill, C.K. Bonsi, and P.A. Loretan (eds.). Sweetpotato technology for the 21 st century. Tuskegee Univ., Tuskegee, Ala.

Prince, R.P. and W.M. Knott. 1989. CELSS Breadboard Project at the Kennedy Space Center, p. 155-163. In: D.W. Ming and D.L. Henninger (eds.). Lunar base agriculture: Soils for plant growth. Amer. Soc. Agron., Madison, Wis.

Rice, E.R. 1984. Allelopathy. Academic, London.

Schuerger, A.C. and D.J. Mitchell. 1992. Effects of temperature, hydrogen ion concentration, humidity, and light quality on disease caused by Fusarium solani f.sp. phaseoli in mung bean. Can. J. Bot. 70:1798-1808. 